Article

\title{
Political Opinion Formation as Epistemic Practice: The Hashtag Assemblage of \#metwo
}

\author{
Sebastian Berg ${ }^{1, *}$, Tim König ${ }^{1}$ and Ann-Kathrin Koster ${ }^{2}$ \\ ${ }^{1}$ Research Group “Democracy \& Digitalization,” Weizenbaum Institute for the Networked Society, 10623 Berlin, Germany; \\ E-Mails: sebastian.berg@wzb.eu (S.B.), tim.koenig@wzb.eu (T.K.) \\ 2 Schaufler Kolleg, Technical University Dresden, 01062 Dresden, Germany; \\ E-Mail: ann-kathrin.koster@mailbox.tu-dresden.de \\ * Corresponding author
}

Submitted: 15 April 2020 | Accepted: 19 June 2020 | Published: 8 October 2020

\begin{abstract}
The article contributes to the literature on the political use of hashtags. We argue that hashtag assemblages could be understood in the tradition of representing public opinion through datafication in the context of democratic politics. While traditional data-based epistemic practices like polls lead to the 'passivation' of citizens, in the digital constellation this tendency is currently challenged. In media like Twitter, hashtags serve as a technical operator to order the discursive fabrication of diverse publicly articulated opinions that manifest in the assemblage of tweets, algorithms and criticisms. We conceptualize such a critical public as an epistemic sensorium for dislocations based on the expression of experienced social imbalances and its political amplification. On the level of opinion formation, this constitutes a process of democratization, allowing for the expression of diverse opinions and issues even under singular hashtags. Despite this diversity, we see a strong tendency of publicly relevant actors such as news outlets to represent digital forms of opinion expression as unified movements. We argue that this tendency can partly be explained by the affordances of networked media, relating the process of objectification to the network position of the observer. We make this argument empirically plausible by applying methods of network analysis and topic modelling to a dataset of 196,987 tweets sampled via the hashtag \#metwo that emerged in the German Twittersphere in the summer of 2018 and united a discourse concerned with racism and identity. In light of this data, we not only demonstrate the hashtag assemblage's heterogeneity and potential for subaltern agency; we also make visible how hashtag assemblages as epistemic practices are inherently dynamic, distinguishing it from opinion polling through the limited observational capacities and active participation of the actors representing its claims within the hybrid media system.
\end{abstract}

\section{Keywords}

\#metwo; assemblages; big data; datafication; democracy; epistemic practices; hashtag; network analysis; topic modelling; Twitter analysis

\section{Issue}

This article is part of the issue "The Ongoing Transformation of the Digital Public Sphere" edited by Emiliana De Blasio (LUISS University, Italy), Marianne Kneuer (Hildesheim University, Germany), Wolf J. Schünemann (Hildesheim University, Germany) and Michele Sorice (LUISS University, Italy).

(C) 2020 by the authors; licensee Cogitatio (Lisbon, Portugal). This article is licensed under a Creative Commons Attribution 4.0 International License (CC BY).

\section{Introduction}

In recent years we could observe 'discursive assemblages' with regard to hashtags as part of the culture of discussion in social networks (Rambukkana, 2015, p. 3). Discussions about hashtags like \#whyididntreport or \#metoo manifest themselves mainly on the Internet, are independent of or precede street movements, and are thereby characterized by using keywords to generate publicity for specific topics. Following this understanding, 
we argue that such hashtag assemblages could be understood as an alternation of the epistemic practices of datafication in the context of democratic politics. We will first lay out how rational and scientific epistemic practices such as opinion polling emerged in democratic contexts, what problems resulted from this, and how the conditions of the digital constellation now enable different formations such as hashtag assemblages. We then stress that the need for objectification through a comprehensive analysis remains relevant, if the added complexity, heterogeneity and 'conflictivity' of hashtag assemblages is not to be lost. Based on an empirical analysis of the case of \#metwo, which dealt with racism, identity and integration in Germany, we discuss the emancipatory potential of hashtag assemblages and conclude with an evaluation of the conditions that allow hashtag assemblages to serve as a representation of public opinion.

\section{Datafication of Public Opinion as Epistemic Practice}

We tend to associate the idea of public opinion primarily with opinion polls, i.e., the epistemic practice of structuring aggregates of individual opinions by market research companies and public relations experts, but rarely with emancipatory democratic practices. However, representations of public opinion have changed significantly over time, from lottery and elections over protests, petitions, or surveys, to leaflets, consultative fish bowls, and, more recently, the evaluation of social media data (McGregor, 2019; Splichal, 2012). Besides obvious continuities in big data analytics, new ways of representing public opinion have emerged as well. The changing media infrastructure has played a significant role in this development, though it would be fallacious to assume some kind of determination or path dependency. New socio-technological conditions provide a relational plurality of affordances, i.e., possibilities of actions depending on "digital actors (firms, governments, as well as digital subjects) and the digital environment" (Ettlinger, 2018, p. 3). This also applies to the differentiated practices through which public opinion is constructed: "In every polity there exist distinctive relationships among conceptions of 'the public,' the dominant techniques for assessing 'public opinion,' and the media through which members of the public may express their desires" (Herbst \& Beniger, 1995, p. 94). Following this idea, we suggest considering hashtag assemblages as a new, experimental way to link "democracy and technology...through a co-evolutionary process of mutual enabling" (Hofmann, 2019, p. 4; cf. Berg, Thiel, \& Rakowski, 2020). They emerge as a different expression of public opinion that is suited to the communicative conditions of a networked communication structure and democratic adjustments like counter-democracy or monitory democracy (cf. Keane, 2018; Rosanvallon, 2008).

The comprehensive social transformation of modernity seemed to dismiss an informed public as a mere phantom (Lippmann, 1993), depriving representative government of an epistemic sensorium for orienta- tion and legitimation, while paving the way for a new paradigm: quantification, and with it approaches such as survey research, objectification, and datafication:

Vexing problems of the industrial age, from poverty and labor unrest to commercial leisure and urban vice, were the proximate cause for both the emerging notion of the 'social' and the invention of tools to observe it. Social surveys were born of this complex. (Igo, 2007, p. 25)

Statistical survey data promised to provide insights into needs and preferences of citizens, a suitable way to access and represent a public opinion that has become illegible. Felix Keller emphasizes this progressive aspect of opinion polls as an attempt to bring citizens together, if not physically in the forum, then diagrammatically in the epistemic practice of statistical representation. The tension fostered:

A dynamic of representation of the 'political audience,' which appropriates the latest knowledge techniques in order to include the audience of the state in the political communication cycle, to represent it in the political order. In this way, ever new figures of the audience emerge: by no means stable figures and also figures that are contradictory in themselves. (Keller, 2007, pp. 153-154)

For contemporaries, datafication combined scientific objectivity with democratic feedback and therefore connected to the political paradigm of government by opinion. For what was coined as a technology of democracy was particularly successful since it ultimately promised to solve a persistent problem:

How does this vague, fluctuating, complex thing we call public opinion-omnipotent yet indeterminatea sovereign to whose voice everyone listens, yet whose words, because he speaks with as many tongues as the waves of a boisterous sea it is so hard to catch-how does public opinion express itself in America? (Bryce, 1995, p. 232)

Due to such new ways of knowing, public voice and the forgotten man had found a new expression and "the firm establishment of a public opinion polling industry...homogenized the definition [of public opinion] and stabilized it for the foreseeable future" (Converse, 1987, p. 13). Especially in its early days, it was framed as an instrument of inclusion and progression in mass society, an epistemic sensorium for social dislocation. Its success was followed by legitimation and cultural power (cf. Moon, 1999).

However, the success of polls was not so much based on their democratic foundations, even though George Gallup in particular succeeded in selling his national town hall meetings as a finger on the 'pulse of democ- 
racy' (Gallup \& Rae, 1940). Much more important was the actual entrepreneurial work of leading figures such as Gallup or Elmo Roper, who came from the advertising industry and knew how to market their technologies of mass feedback to the government (Beniger, 1983, p. 483). The criticism of this conceptual revaluation is abundant: Lindsay Rogers (1940) early on emphasized the plebiscitary dimension of this technology and stressed that polls are no technological fix for the practical problems with direct democracy for they cannot grapple with the need to craft compromises. Blumer (1948) pointed out that the individualistic reconstruction of opinions leaves the structures of social organization and power unreflected (cf. Bourdieu, 1979). Later on, Habermas criticized the socio-psychological revaluation of behaviorism that devalues the intersubjective formation of opinion and judgement, reframing a critical public to an object of communicative manipulation (Habermas, 1991).

These criticisms are still justified as new forms of 'scraping the demos' emerge, meaning "practices of gaining information about citizens through automated analysis of digital trace data which are re-purposed for political means" (Ulbricht, 2020, p. 427; cf. Anstead \& O'Loughlin, 2015). The rationality of big data analytics is precisely aimed at perpetuating and enhancing the legitimacy of quantified and datafied knowledge practices to represent democratic voices that spread in other fields of society-even activism, as David Karpf points out with respect to activist organizations like MoveOn.org: This idea that "some of the most important impacts of digital technology lie not in the capacity of disorganized masses to more easily speak, but in the capacity...to more effectively listen" (Karpf, 2017, p. 1) resonates with Beniger's observation:

That the historical significance of surveys is not, like the older communications media of elections and social movements, to enable us to speak our minds. It is rather to enable those who commission the surveys to find out what is on our minds-whether we want to tell them or not. (Beniger, 1983, p. 479)

These asymmetrical relations between the scraper and the scraped hardly strengthen inclusion or subaltern positions, as the pollsters have claimed. On the contrary, epistemic practices like predictive analytics rather afford populist performances based on the claim to possess true knowledge on the will of the people (Baldwin-Philippi, 2019; cf. Urbinati, 2019; Gerbaudo, 2012). It can therefore be concluded that the quest for an epistemic practice suited to democratic requirements has by no means been resolved in the digital age. However, the shared stories which constitute hashtag assemblages now seem to offer an opportunity to generate an epistemic sensorium for societal problems that takes up the promises of democratic inclusion once again and thereby in some aspects moves closer to the early promises of opinion research.

\subsection{Hashtag Assemblages: (New) Epistemic Practice of Public Opinion}

In the course of digitalization, a restructuring process is taking place, which sociologist Andreas Reckwitz describes as the 'culturalization of the technological' (Reckwitz, 2017, p. 227): Modernity was characterized by an industrial rationality, which found its expression especially in processes of standardization leading to an adjustment and unification of modes of behavior. Cultural forms of action and expression were influenced to a significant degree by forms of 'doing generality.' This applies to the specific field of industrial production as much as to the rational standardization of individual behavior in various forms of surveys and the concept of opinion polls in mass society (Herbst, 1993, p. 61).

In the digital constellation, however, practices of standardization are increasingly being replaced by new logics. A "technological reversal is taking place: from the technical culture of industrial modernity to the cultural machine of late modernity" (Reckwitz, 2017, p. 228). Here, practices of digitalization play a significant role. The universal medium of the Internet emerged as an 'architecture of participation' (Healy, 2015, p. 190) and enabled cultural forms of sense making which are no longer oriented to the paradigm of generality, but to decentralization and diversity. This constellation enables communicative assemblages of meaning to emerge and be shaped in a different and accessible way, even for complex societies and dispersed groups of people, through the entanglement of mass media with the grounding principles of social media, i.e., programmability, popularity, connectivity and digital datafication (van Dijck \& Poell, 2013, pp. 5-7; cf. Reckwitz, 2017, p. 230). All citizens with access to the Internet and digital devices are basically able to participate in debates on social media, including attempts to change, discredit or reinforce them. Since these assemblages are technically based on formal computerization, they can also be sorted and ordered as media becomes programmable (Manovitch, 2001, p. 27), thus revaluing the hashtag for communicative action. The hashtag enables users to "create links independently and without any knowledge of programming, and thus...paved the way for the highly praised 'social' and participatory era of the internet" (Bernhard, 2019, p. 3). Correspondingly, the hashtag allows for assemblages to emphasize dynamism and subaltern agency in issue definition by appropriating the technological logic of algorithms. In converting a large number of personal experiences about social imbalances through narrative and programmable connectivity, they allow their experience to amplify and reach a threshold where debates become newsworthy for established outlets in the hybrid media system, fostering a politicization of such issues (Phillips, 2018).

Hashtag assemblages also afford political actors or journalists a new form of the epistemic sensorium, allowing "for a more public, relational, and temporally 
sensitive representation of public opinion" (McGregor, 2019 , p. 4). However, this complexity does not necessarily translate into an appropriate rendering. Although the research literature predominantly acknowledges the heterogeneity of the groups and confirms the opinion struggles that take place within them (cf. Drüeke \& Zobl, 2013), with reference to the reporting by media outlets, however, there is a much stronger emphasis on the homogeneity and uniformity of the hashtag. Rather than treating hashtag assemblages as dynamic and multifaceted discursive spaces, their representation in media and public debate oftentimes reduces them to a unified movement, a singular voice. As such, digital opinion formations are conceived as an expression of social issues that, while open-ended on their input side, somehow qualify a singular reading of their output. In this way, public opinion treats hashtag assemblages as an epistemic sensorium in line with earlier practices such as polling. What remains disregarded, however, is how the access to this data is mediated by the platforms' networked structures and intrinsic affordances. Contrasting this notion, we would like to evaluate a hashtag's heterogeneity for a specific case, that is \#metwo.

\section{The Case of \#metwo}

The empirical case is concerned with a public debate in Germany, emerging in the aftermath of the FIFA World Cup. What initiated the debate was a statement from leading team player Mesut Özil, whose parents were born in Turkey and came to Germany as guest workers in the 1960s. He accused high officials of the German Football Association as well as some football fans of racist afflictions against his person (Özil, 2018). The event then led to a nationwide debate on racism and integration in Germany. On Twitter, this debate became viral after a call to action from activist Ali Can sprouted into a multifaceted chorus of Germans narrating their experiences with racism. The initiator urged his followers in a video to tell a personal story about their experience with a migration background in Germany: "Let's show in a post that we stand against racism! I am not only German because I follow their rules or am successful. I am always German - as much as I am the other" (Perspective Daily, 2018, own translation). Correspondingly, the hashtag \#metwo was chosen to indicate the split between two identities felt by many Germans with a migration background. Many tweets reported racist and discriminatory experiences from everyday life, in particular exclusion, humiliation through insults or physical violence but also disadvantages and non-recognition in school and working life. Eventually, the issue would be picked up by politicians, such as foreign minister Heiko Maas and Federal President Frank-Walter Steinmeier (Topçu, 2018).

While Twitter's user base in Germany remains relatively small with an estimated $12 \%$ of the population using the platform (whereas the most popular social media platform, Facebook, reaches 50\%; Newman, Fletcher,
Kalogeropoulos, \& Nielsen, 2019, p. 87), its popularity among politicians and journalists gives it increasing potential for agenda setting (Jungherr, 2016). Accordingly, news outlets were quick to discuss the hashtag \#metwo in their online sections. By mid-August, articles on the topic were published in almost all major German news outlets' online publications (for an overview of articles published in German news outlets, see Appendix 1 in the Supplementary File). Their content ranged from personal narratives and debates on racism in German society to comments on and criticism of the movement. What all of these reports and comments had in common, however, was the depiction of the hashtag as a unified movement sharing the same goals and agenda. This assumption is in part due to the affordances of Twitter as a platform, which quantifies tweets by their hashtags and promotes these as 'trending topics' when a certain threshold is reached. In that sense, every user utilizing the hashtag is contributing to the trending of certain topics, which in turn helps news outlets to assess which Twitter topics have become relevant for a larger audience. At the same time, data access for users of the platform is mediated by follower networks, affording effective information diffusion primarily between relatively homophilic users (Barbera, 2013; Myers, Sharma, Gupta, $\&$ Lin, 2014). These affordances can conceal the fact that the use of a certain hashtag does not necessarily imply a shared agenda but can just as easily indicate criticism, reframing and attempts at hijacking. As we shall see, this one-dimensional reading of hashtag assemblages by actors employing this epistemic sensorium overlaps with their relative position within the Twitter network surrounding the hashtag \#metwo.

\subsection{Methods and Data}

In order to analyse the multifaceted and normatively charged discursive space convened under \#metwo, we conducted an in-depth analysis of Twitter data. Sampled via the hashtag \#metwo from both Twitter's REST and Stream API, we retrieved a total of 196,987 tweets between July 27th (about two days after the hashtag had been spawned) and August 31st (when the discussion had died down considerably). This sample allowed us to examine the discourse from its original intention to a contested space of competing narratives. To investigate this shift, we employed a number of methods in order to analyse both the networks found within the sample and the topics discussed between their members. Apart from descriptive analyses concerning the occurrence of additional hashtags in the sample, we employed the Louvain algorithm to detect communities. This algorithm aims to maximize modularity via a 'greedy' approach, with its implicit notions of hierarchy and self-similarity resembling the communities naturally found in social networks (Blondel, Guillaume, Lambiotte, \& Lefebvre, 2008). Mentions, replies, quotes and retweets between users formed the (directed) edges 
of the network so analyzed. Communities containing more than $2 \%$ of the total user population were classified via their five most influential users as determined by their PageRank (Brin \& Page, 1998). In line with assumptions about the platform's power-law distribution (Myers et al., 2014), these users' Twitter profiles and tweets in the sample served as proxy for identifying the political affiliations and structural positions most strongly shaping opinion formation within communities. Via the stm package for R (Roberts, Stewart, \& Tingley, 2019), a structural topic model was employed to identify meaningful topics within the sample before calculating their prevalence in the detected communities. Hashtags used and the day of the tweet's publication were employed as prevalence variables in the structural topic model, allowing us to take into account both hashtag-based classifications of content and the fluctuation of topics over time to improve results. In order to assure reproducibility and stability of the model, the spectral method of initialization was employed (Roberts, Stewart, \& Tingley, 2016). Following methodological suggestions of Schofield and others, words were lemmatized and stopwords removed only after computation of the model (Schofield, Magnusson, \& Mimno, 2017; Schofield \& Mimno, 2016). In line with guidelines of Roberts et al. $(2016,2019)$, we employed statistical measures to evaluate topic models with different numbers of topics before settling on a model with 15 topics. These topics were then classified by most strongly associated words and clearly assigned tweets. The results were controlled with the results of a qualitative analysis of a subsample of tweets. By manually reviewing 1,000 randomly selected tweets from the first two days in the sample, we vali- dated the correspondence between the topics found by the model and those raised by the users in the sample.

\subsection{Co-Occurring Hashtags and Subdiscourses}

Considering hashtags as markers for discursive spaces, an analysis of the co-occurring hashtags under \#metwo reveals multiple subdiscourses, each with their own agenda and temporal dynamics (see Figure 1). For the purpose of this analysis, we examined the 10 most frequent co-hashtags in terms of their dynamics and content. While \#deutschland (\#germany) und \#rassismus (\#racism) are rather self-explanatory and give context to the debate, the remaining hashtags constitute subtopics and apply framing not apparent in the hashtag \#metwo. For example, activist Ali Utlu initiated \#mygermandream and its synonym \#germandream to describe positive experiences by migrants and Germans with a migration background, as well as hopes for a multicultural Germany, thus forming the (brief) counter narrative to \#metwo. Mentions of \#özil, on the other hand, connect to the debate about football player Mesut Özil leaving the German national team, which spawned the larger debate about racism in Germany and the hashtag \#metwo. \#metoo links the debate to the correspondent debate on sexism while \#mequeer spawned a subdiscourse on discrimination against LGBTQIA* people. The co-use of these two hashtags with \#metwo points to experiences of intersectional discrimination.

In contrast to these discourses, \#kochallenge was used as a marker for a narrative about 'violent migrants' who assault elderly people as part of a 'challenge.' The sharp rise and decline in the sample points to an attempt

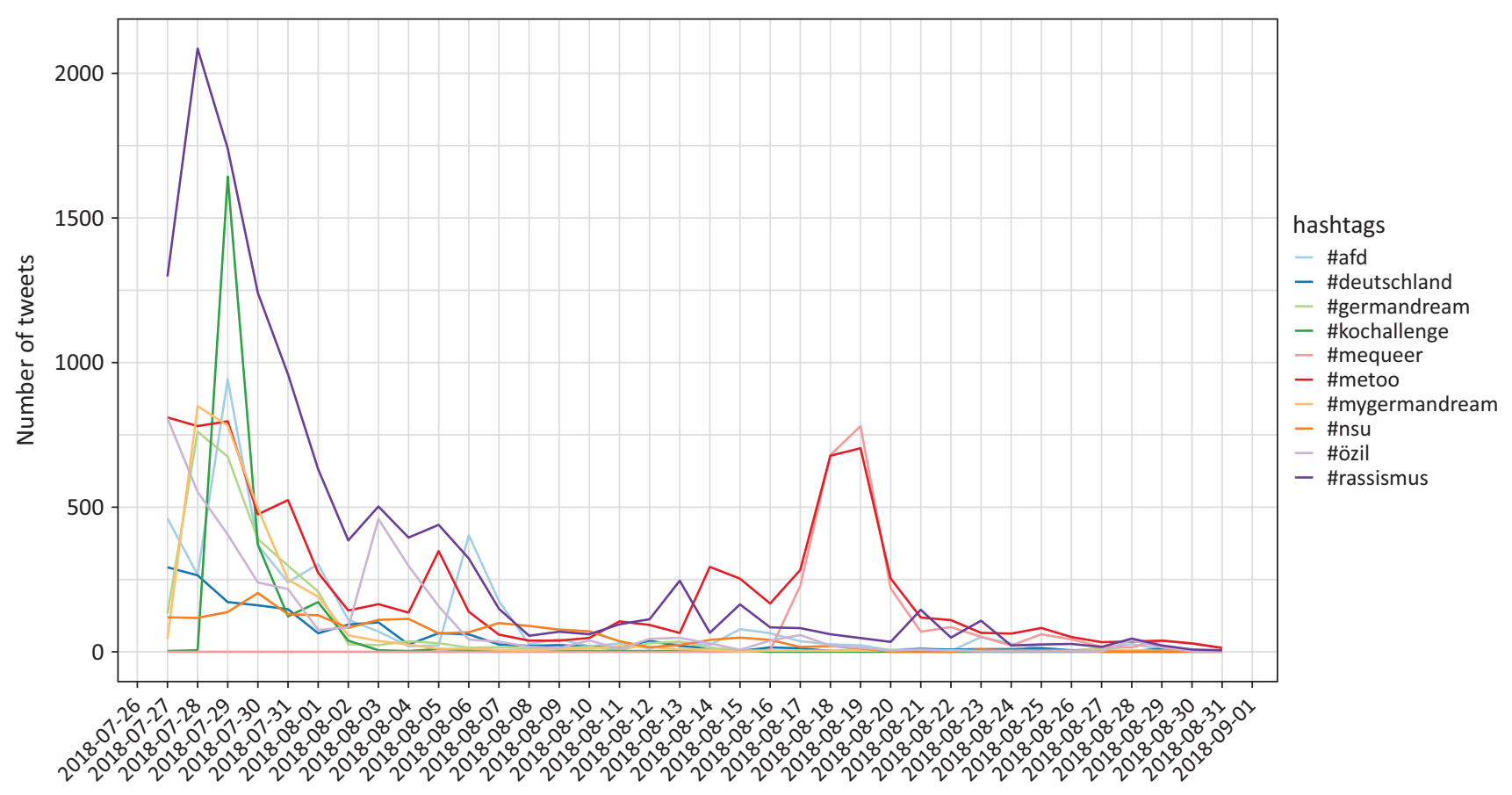

Figure 1. 10 most frequent co-occurring hashtags in the sample over time. 
at hijacking and discrediting the discourse by reversing victimhood. Meanwhile, \#afd references the German farright party Alternative für Deutschland (AfD) both positively (as an alternative to 'over-migration' and the 'politically correct' debate of \#metwo, as its co-occurrence with the \#kochallenge indicates) and negatively (as a driver of racism in Germany). Lastly, \#nsu is concerned with the murders carried out by the extreme-right terror organization NSU (National-Socialist Underground) and conspiracy theories about their alleged cover-up. These narratives, for the most part, include the purported involvement of migrant criminals and the Turkish secret service, and thereby attempt to reframe the murders as an issue external to German society rather than acknowledge structural racism. Most of these tweets can be found in the vicinity of a particular account named @nsu_leaks, which can be regarded as an extreme-right conspiracy hub. The appearance of these tweets under \#metwo, again, points to an attempted hijacking of the discourse.

In sum, the analysis of the co-occurring hashtags in the sample reveals two things: the fragmentation of the discourse into vastly different subtopics and the intention of certain actors to reframe the debate for their own political purposes. While some of these frames work to broaden the agenda of the original debate, others aim to disturb and discredit it. And even though these subdiscourses may in themselves contain contestation and discussion, they reveal the variety and embeddedness within overlapping discourses rarely reflected in the public perception of political hashtags.

\section{3. \#metwo Networks}

Figure 2 shows the network graph with users colored according to their community membership, revealing a fragmented network of diverse communities. The largest community we found is what we call the 'sincere' \#metwo community. The highest-ranking users are activists who shared personal stories about experienced racism and the debate as well as the left-leaning news outlet taz (tazgezwitscher) commenting favorably on the hashtag. The second largest community in the network is what we termed the 'right-wing community.' On the one hand, this community's most prominent users include influential, seemingly 'ordinary' users without party affiliations, but on the other hand, there are also many within this community who represent distinct political persuasions such as the conservative journalist Birgit Kelle (Die Welt) and the AfD politician Jens Eckleben. All shared content either criticizing the debate or reframing it in terms of racism against Germans or violent migrants (e.g., via the hashtag \#kochallenge). Further clusters formed around Özil (who, despite being extensively referenced, never posted under \#metwo himself), \#metwo initiator Ali Can, and news outlets commenting on the issue-in particular the outlet Zeit Online. Interestingly, we could observe a cluster characterized by politicians, including the Minister of Foreign Affairs Heiko Maas, tweeting under the hashtag. Another community of particular interest formed around the hashtag \#germandream and its initiator, Ali Utlu. This cluster was also characterized by green party politician Cem Özdemir's and journalist Düzen Tekkal's personal narratives on the issue as well as, interestingly, BILD reporter Filipp Piatov, who commented on how white men are underprivileged in the \#metwo debate. Two additional communities were characterized by either left-wing activists or web personas such as bloggers and youtubers as their most influential users.

The plurality of communities tweeting under the hashtag \#metwo illustrates not only the various actors within the seemingly unified hashtag public, but also their interaction with each other. This interaction is illustrated in Figure 3 (for relative interaction values see Appendix 2 in the Supplementary File). While it may be surprising to some to find such strong activity by rightleaning and extreme-right activists under a seemingly leftist hashtag, we can also see how their interaction is strongly self-referential, with the community's strongest outgoing connection being to the \#germandream community. While the sincere \#metwo community also strongly references its own members, it is the most frequent outgoing connection for all communities except the right-wing. This means that this community remained at the core of the debate, acting as a point of reference for other actors, such as news outlets or politicians, shaping public perception of the hashtag with its content. Reciprocally, content from the communities surrounding news outlets, the web community and Ali Can was picked up by the \#metwo community. The strong right-wing community, in contrast, attempted to criticize and lay claim to the debate. As the analysis shows, however, these attempts were not picked up by the broader audience, as only a small share of content from this community was referenced by other communities. The rightwing community, even though the second largest community in the sample, therefore had limited influence on the broader debate and remained unable to reframe the hashtag assemblage with their agenda. As such we can see that the perception of a hashtag assemblage must be shaped by the network position of the actors utilizing Twitter as an epistemic sensorium. The central position of the \#metwo community allowed for the shaping of the debate, contributing to the perception of a unified movement by news outlets and politicians in the public debate both on- and off-platform. While large in numbers and highly active, the right-wing community did not manage to make itself heard in the broader debate, as its content was not picked up by actors outside the community. In other words, it is highly likely that the issues indicated by the hashtag \#metwo were perceived adversely between the right-wing and the \#metwo communities. Due to its different uptake by public actors, however, the sincere \#metwo narrative prevailed. 


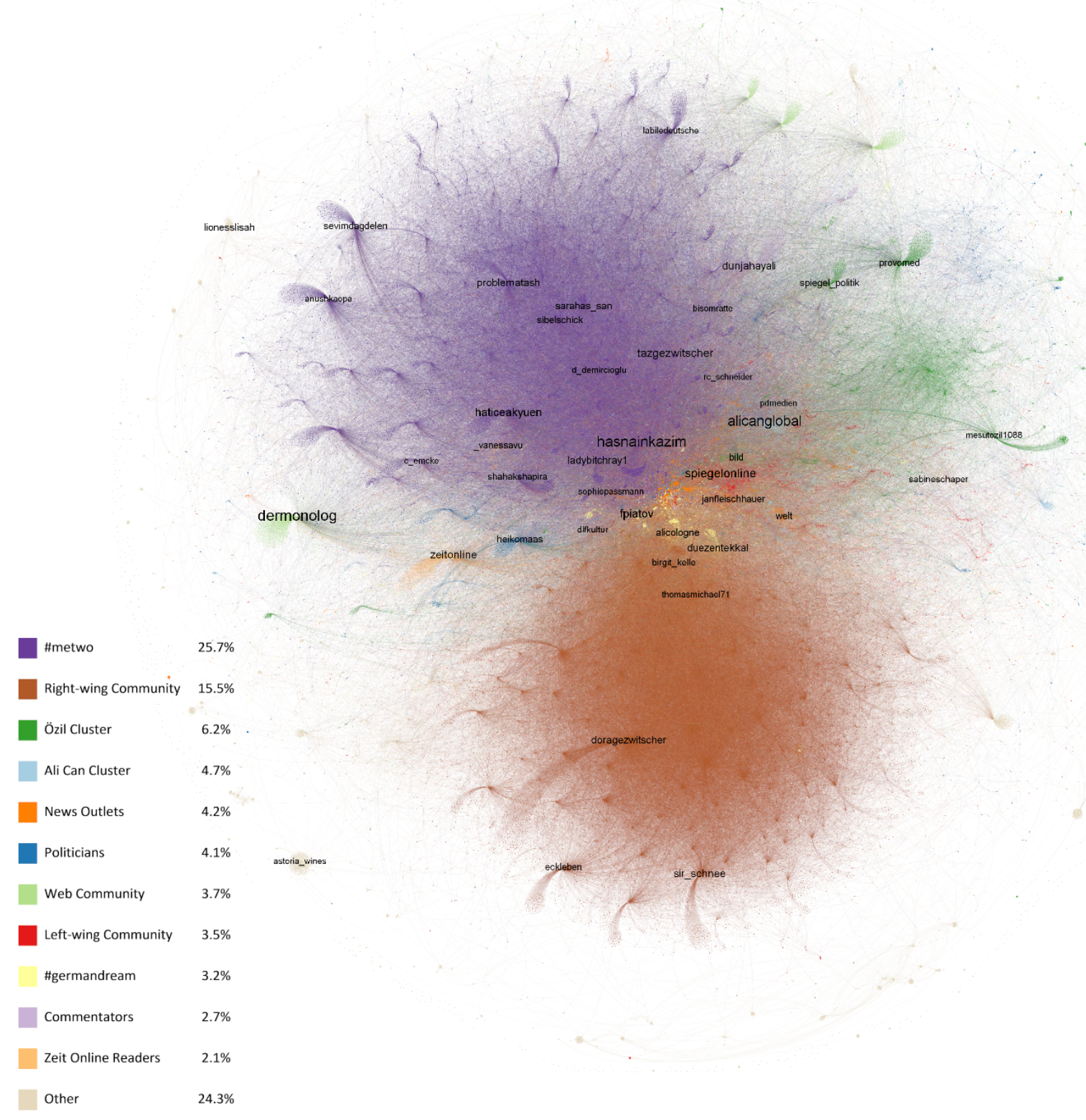

Figure 2. Network graph of communities. Node and label sizes according to PageRank. Share of communities annotated in legend. Graph layout with ForceAtlas2 (Jacomy, Venturini, Heymann, \& Bastian, 2014) in Gephi (Bastian, Heymann, \& Jacomy, 2009).

\section{4. \#metwo Topics}

In order to verify a different discourse between communities, we analyzed the results of the structural topic model and calculated the distribution of topics within the communities described above. The results can be found in Figure 4, with exact numbers reported in Appendix 3 in the Supplementary File. We will point to a few results of interest. For one, the matter of implications and justifications of the debate, including whether or not people have a right to 'complain' about racism via the hashtag, was discussed most often by commentators and the web community. This topic also had the biggest share of the debate in the \#metwo community, with reports on the matter popular there as well. In this community, personal stories of experienced racism (especially concerning education) were most prevalent across communities. The broader debate on racism and integration in Germany was most strongly picked up by commentators, the community of Zeit Online readers, and politicians. The topic also held a considerable share within the community of news outlets. While opinions on these matters in the sample are by no means unified, the sparking of this very debate had been one of the main goals of \#metwo's initiators. This topic's distribution among communities representing actors relevant in society beyond 


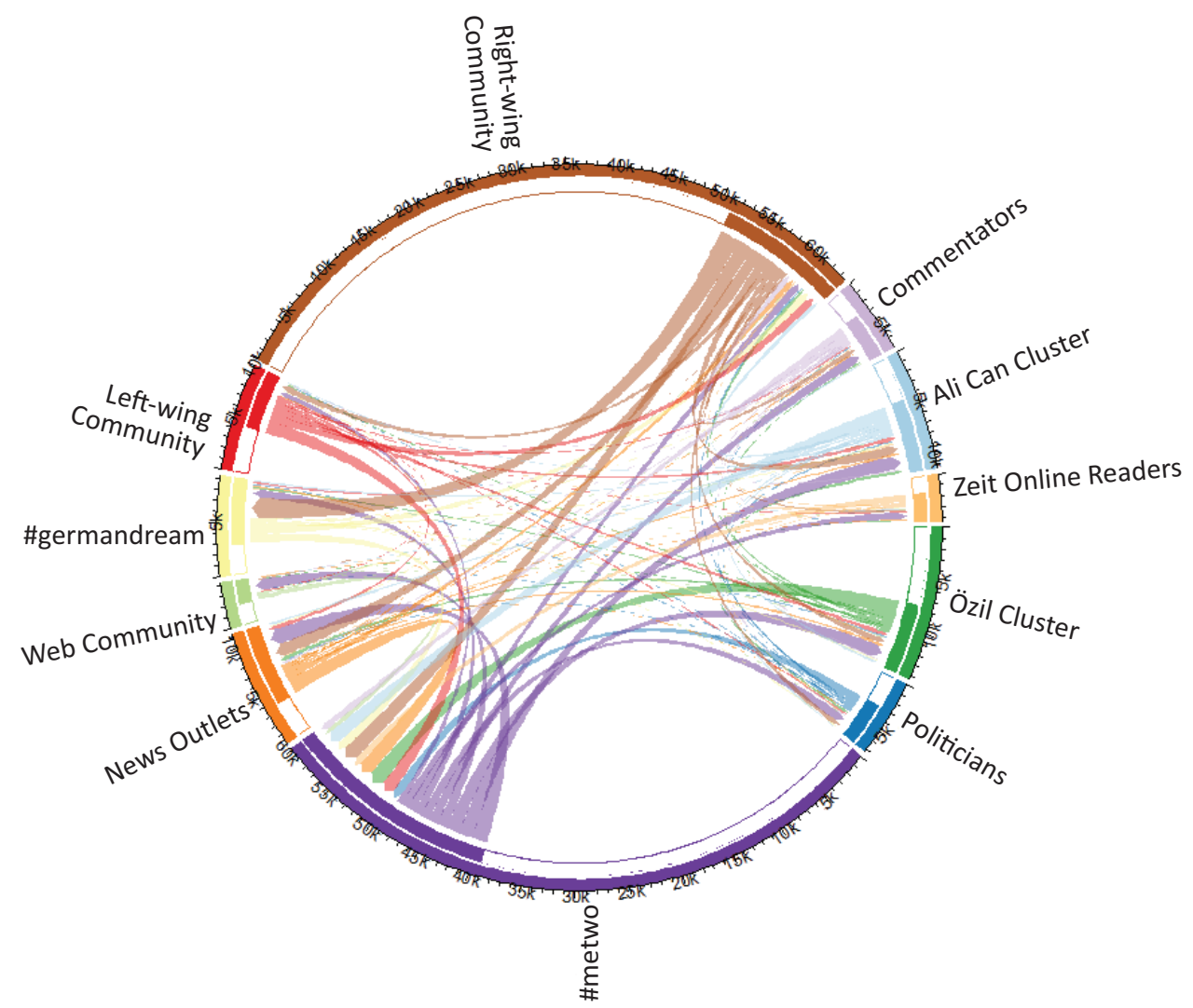

Figure 3. Community interaction in absolute numbers of tweets in thousands. White area indicates the share of interaction within communities. Visualization via circlize (Gu, Gu, Eils, Schlesner, \& Brors, 2014).

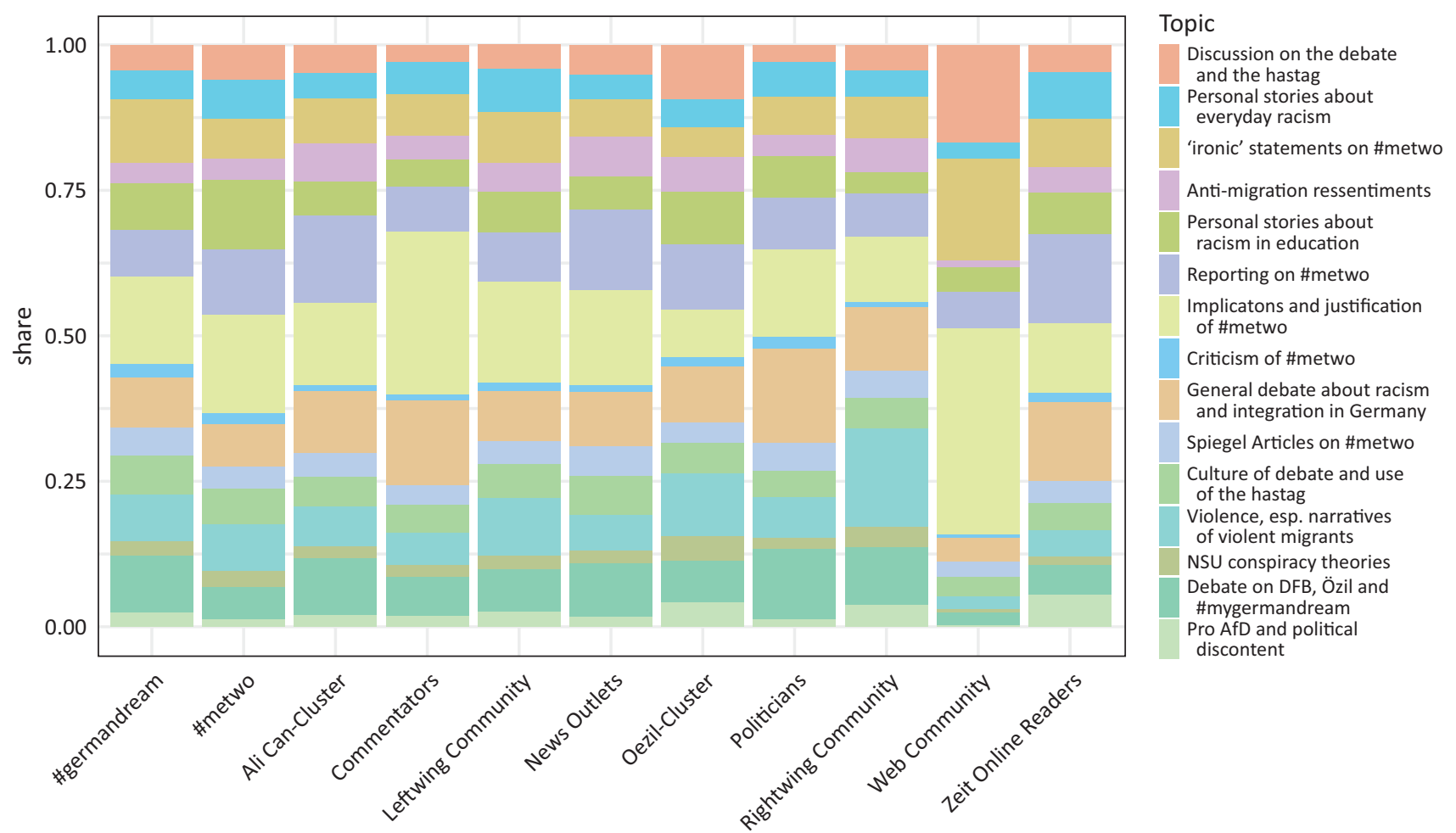

Figure 4. Topics found under the hashtag \#metwo and their relative share of tweets within communities. 
Twitter may well be one of the reasons that the debate, which started on the platform, reached a larger audience and led to further political action.

Anti-migration resentments as well as political discontent and pro-AfD statements were distributed among communities relatively evenly. This can be attributed to the fact that these statements are mainly found as replies to other tweets, especially news articles, and thus disseminated across communities. While also discussing the topics of the hashtag's implications as well as racism and integration in Germany, the most frequent topic within the right-wing community centers on stories of violence. A closer analysis revealed that, in this community, the topic consists mostly of narratives of violent migrants, especially under the hashtag \#kochallenge. As such, this topical framing was an attempt to shift victimhood from migrants and their experiences of racism to Germans and their (alleged) experiences of violence at the hand of migrants. The topic of football player Özil, the German Football Association (Deutscher Fußball Bund) and, in this context, the hashtag \#mygermandream, was a matter of debate in most communities outside of the sincere \#metwo one. This topic was most popular in the community characterized by politicians, followed by the one characterized by the \#germandream initiator and the right-wing community. This shows how the attempt to reframe the discourse in less critical terms through narratives of successful migration in Germany intersects with the broader debate about Özil, which initially started the critical hashtag \#metwo. This reframing as a potential solution to the issues raised resonates particularly well with more conservative actors, such as politicians and certain members of the right-wing community.

In sum, these results point to a fragmented discourse in topics, users and political intentions within the seemingly unified hashtag \#metwo. Instead of a united community with a clear agenda, there were different claims being made to the hashtag and attempts to steer the discourse in service of various political goals, including the negation of Ali Can's original goal: exposing the racism in German society that impacts citizens' everyday life. The prevalence of certain discourses both on the platform and in the broader public debate can be attributed to the interaction within and between communities. The issues detected in a hashtag assemblage as an epistemic practice therefore not only depend on open-ended user input, but also are equally dependent on the visibility of these positions as shaped by the affordances of the platform and its users' preferential content consumption. The content ascribed to a hashtag, therefore, is not an objective constant, but rather a process as dynamic and subjective as its formation.

\section{The Epistemic Practice of Hashtag Assemblages}

The empirical analysis emphasized three positive aspects in particular that hashtag assemblages offer as epistemic practice of opinion formation. First, they enable persons affected by social problems to represent their issues in their own choice of expression, contributing to the valorization of subaltern agency. But, as the analysis made clear, they can also be related to a wide range of other problems, situating those problems intersectionally in an assemblage of different, but connecting experiences. Second, it not only allows those citizens affected to raise their voice(s), but anyone to oppose or comment on these claims. The analysis revealed the variety of communities posting under the hashtag. The fragmentation into those communities has to be acknowledged, making it all the more important for third parties like journalists to not only represent one opinion as the main claim of the hashtag, but to engage with the conflictive, multifarious portfolio of the assemblage. Both aspects relate to a third one: the dynamic character of hashtag assemblages. The assemblage does not represent a reflection of social preferences, but political arguing and judgment formation in the making, shaping the issue concerned, its scope and implications.

As an epistemic practice, it enhances the civic part of opinion formation, i.e., "the more informal processes of knowledge making by which states and their citizens arrive at collective settlements regarding the epistemic foundations of public life" (Miller, 2008, p. 1896). Be it the questions asked and issues raised in traditional surveys or the use of statistical or machine learning models to mine users in social networks, opinion polling and 'demos scraping' empower the epistemic authority of experts on the basis of specific knowledge regimes. In contrast, hashtag assemblages bring the forgotten man and woman back in right from the start. Marking tweets with a hashtag serves as a shibboleth to a political public and allows a plurality of voices to contribute their own experience to the opinion-forming process.

However, one should not fall for the 'myth of us' and mistake contributions on social media platforms to be a natural expression of political collectivity or the will of the people (cf. Couldry, 2015). Hashtag assemblages are a representation, embedded in social hierarchies and power structures on social media. Even though hashtag assemblages are basically open to all citizens, they are still affected by gaps in participation based on economic or technological inequality, resulting in another form of epistemic inequality (cf. Dalton, 2017). Twitter is an elitist medium, especially in Germany. A significant share of tweets relates to established news outlets while central hubs, like Hasnain Kazim or Spiegel Online, benefit from their social connections in the hybrid media system, as measured in scope or number of followers. For the journalist or politician looking to infer social issues from these assemblages, their own network position on the platform may crucially shape the access to the very data they are looking to utilize. At the same time, these actors' participation may significantly shape the discourse entailed by the hashtag due to their position in the hybrid media system. As such, the epistemic practice of reading a hashtag assemblage is as dynamic as its creation. 
In the democratic representation of social issues, a practice of objectification remains irreplaceable. Since there is no direct access to reality, a form of structured abstraction is needed to represent the issues at hand. For opinion polling, this process has been shaped by scientific principles, leading to a highly structured formation process and an objectification mostly independent from the observer's perspective. As such, they had the great advantage of being able to generate objectivity in a form of a general and abstract representation. The analysis shows, however, that, for hashtag assemblages, this representation is highly dependent on the observer's perspective, mediated by dynamic network structures. While the open-ended forms of participation afforded by these platforms hold great potential as an epistemic sensorium, the perspective of the Twitter interface does not allow for an objective representation but instead is designed for dynamic participation within the assemblage. For hashtag assemblages, there is a double contingency in the process of objectification: It is inscribed both in its formation and observation. The open-endedness of input is accompanied by a strong dependency on the network position of the observer. As such, the representation of a hashtag assemblage depends not only on the input, but also on the visibility of input to actors that can further disseminate and act on the issues at hand. As demonstrated by the analysis, counternarratives of the hashtag were unable to prevail within the broader debate, as their highly active proponents within the rightwing community were unable to disseminate their message. Rather, the perspective of the centrally situated, sincere \#metwo community dominated the public debate, allowing their rightful criticism against social injustice to be heard by a broader audience.

For actors that rely on the bigger picture in order to assess these representations of public opinion in a way that acknowledges complexity, heterogeneity and its conflictual formation, digital tools such as network analysis and quantitative text analysis can provide the methods for a more objective representation by fostering a form of reflection and 'trained judgement' (Daston \& Galison, 2007). However, even an inclusive and reflexive epistemic sensorium for social dislocation does not ensure a political solution. Especially complex forms of social inequality and racism are persistent and granular, preventing easy solutions. The awareness raised in hashtag assemblages, however, may at least point to existing problems and by chance provide the participants with the knowledge that they are not alone, but that their issues are collective political problems.

In conclusion, the condensation of individual and diverse narratives in large numbers, the "power of the...concept data" (Rosenberg, 2018), is combined with the "power of the narrative form" (Yang, 2016): the capability to take part in the framing, to provide experience and meaning, to steer audience participation and understanding. It emphasizes the importance of subjective experience and participation to constitute a public opinion on social and political problems: "Big data delivers numbers; thick data delivers stories" (Wang, 2013). Hashtag assemblages can be subscribed under the logic of counter-publics or monitory democracy. Above that they can also connect to the early and progressive tradition of datafication as epistemic practice, giving it a new, emancipatory twist. If this emancipatory potential of hashtag assemblages is to be fulfilled, however, the dynamic nature and the double contingency inherent in their process of representation must be fully taken into account.

\section{Acknowledgments}

We would like to acknowledge the role of the Weizenbaum Institute for the Networked Society, Berlin, where the research has taken place; and the support of the University of Hildesheim and the participants of the international workshop "Transformations in the digital age \#1: Transformations of the Public Sphere" in April 2019 for providing a venue for discussion of an earlier draft of the article.

\section{Conflict of Interests}

The authors declare no conflict of interests.

\section{Supplementary Material}

Supplementary material for this article is available online in the format provided by the author (unedited).

\section{References}

Anstead, N., \& O'Loughlin, B. (2015). Social media analysis and public opinion: The 2010 UK general election. Journal of Computer-Mediated Communication, 20(2), 204-220.

Baldwin-Philippi, J. (2019). The technological performance of populism. New Media \& Society, 21(2), 376-397.

Barbera, P. (2013). Birds of the same feather tweet together. Bayesian ideal point estimation using Twitter data. Paper presented at the APSA 2012 Annual Meeting Paper. https://doi.org/10.2139/ssrn. 2108098

Bastian, M., Heymann, S., \& Jacomy, M. (2009). Gephi: An open source software for exploring and manipulating networks. In Proceedings of the Third International AAAl Conference on Weblogs and Social Media (pp. 361-362). Palo Alto, CA: AAAI Press.

Beniger, J. R. (1983). The popular symbolic repertoire and mass communication. Public Opinion Quarterly, 47(2), 479-484.

Berg, B., Thiel, T., \& Rakowski, N. (2020). Die digitale Konstellation. Eine Positionsbestimmung [The digital constellation. An location of current positions]. Zeitschrift für Politikwissenschaft. Advance 
online publication. https://doi.org/10.1007/s41358020-00207-6

Bernhard, A. (2019). Theory of the hashtag. Cambridge: Polity Press.

Blondel, V. D., Guillaume, J.-L., Lambiotte, R., \& Lefebvre, E. (2008). Fast unfolding of communities in large networks. Journal of Statistical Mechanics: Theory and Experiment, 2008(10). https://doi.org/10.1088/ 1742-5468/2008/10/P10008

Blumer, H. (1948). Public opinion and public opinion polling. American Sociological Review, 13(5), 542-549.

Bourdieu, P. (1979). Public opinion does not exist. In A. Mattelart \& S. Siegelaub (Eds.), Communication and class struggle (pp. 124-130). New York, NY: International General.

Brin, S., \& Page, L. (1998). The anatomy of a large-scale hypertextual web search engine. Computer Networks and ISDN Systems, 30(1), 107-117.

Bryce, J. (1995). The American commonwealth. Indianapolis, IN: Liberty Fund.

Converse, J. M. (1987). Survey research in the United States. Roots and emergence 1890-1960. Berkeley, CA: University of California Press.

Couldry, N. (2015). The myth of 'us.' Digital network, political change and the production of productivity. Information, Communication \& Society, 18(6), 608-626.

Dalton, R. J. (2017). The participation gap. Social status and political inequality. Oxford: Oxford University Press.

Daston, L., \& Galison, P. (2007). Objectivity. New York, NY: Zone Books.

Drüeke, R., \& Zobl, E. (2013). Online feminist protest against sexism: The German-language hashtag \#aufschrei. Feminist Media Studies, 16(1), 35-54.

Ettlinger, N. (2018). Algorithmic affordances for productive resistance. Big Data \& Society, 5(1), 1-13.

Gallup, G., \& Rae, S. F. (1940). The pulse of democracy. The public-opinion poll and how it works. New York, NY: Simon and Schuster.

Gerbaudo, P. (2012). Tweets and the streets: Social media and contemporary activism. London: Pluto Press.

Gu, Z., Gu, L., Eils, R., Schlesner, M., \& Brors, B. (2014). Circlize implements and enhances circular visualization in R. Bioinformatics, 30(19), 2811-2812.

Habermas, J. (1991). The structural transformation of the public sphere. An inquiry into a category of bourgeois society. Cambridge, MA: MIT Press.

Herbst, S. (1993). Numbered voices. How opinion polling has shaped American politics. Chicago, IL, and London: The University of Chicago Press.

Herbst, S., \& Beniger, J. R. (1995). The changing infrastructure of public opinion. In J. S. Ettema \& D. C. Whitney (Eds.), Audiencemaking. How the media create the audience (pp. 95-114). London: SAGE Publications.

Hofmann, J. (2019). Mediated democracy. Linking digital technology to political agency. Internet Policy Review, 8(2), 1-18.
Igo, S. E. (2007). The average American. Surveys, citizens, and the making of a mass public. Cambridge, MA: Harvard University Press.

Jacomy, M., Venturini, T., Heymann, S., \& Bastian, M. (2014). ForceAtlas2, a continuous graph layout algorithm for handy network visualization designed for the Gephi software. PLOS One, 9(6). https://doi.org/ 10.1371/journal.pone.0098679

Jungherr, A. (2016). Twitter use in election campaigns: A systematic literature review. Journal of Information Technology \& Politics, 13(1), 72-91.

Karpf, D. (2017). Analytic activism: Digital listening and the new political strategy. New York, NY: Oxford University Press.

Keane, J. (2018). Power and humility: The future of monitory democracy. Cambridge and New York, NY: Cambridge University Press.

Keller, F. (2007). Figuren des Publikums. Politischer und diagrammatischer Raum [Figures of the audience. Political and diagrammatic space]. In I. Schneider \& I. Otto (Eds.), Formationen der Mediennutzung. II. Strategien der Verdatung (pp. 153-170). Bielefeld: Transcript.

Lippmann, W. (1993). The phantom public. New Brunswick and London: Transaction Publishers.

Manovitch, L. (2001). The language of new media. Cambridge, MA: MIT Press.

McGregor, S. C. (2019). Social media as public opinion: How journalists use social media to represent public opinion. Journalism, 20(8), 1070-1086.

Miller, C. A. (2008). Civic epistemologies. Constituting knowledge and order in political communities. Sociology Compass, 2(6), 1896-1919.

Moon, N. (1999). Opinion polls. History, theory, practice. Manchester and New York, NY: Manchester University Press.

Myers, S. A., Sharma, A., Gupta, P., \& Lin, J. (2014). Information network or social network? The structure of the twitter follow graph. In Proceedings of the 23rd International Conference on World Wide Web (pp. 493-498). New York, NY: Association for Computing Machinery. https://doi.org/10.1145/ 2567948.2576939

Newman, N., Fletcher, R., Kalogeropoulos, A., \& Nielsen, R. (2019). Reuters institute digital news report 2019. Oxford: Reuters Institute for the Study of Journalism. Retrieved from http://www.digitalnewsreport.org

Özil, M. (2018, July 25). Aus! Aus! Das Spiel ist aus! Oder doch nicht? [It's over! It's over! The game is over! Or is it?]. The European. Retrieved from https://www.theeuropean.de/mesut-oezil/14424die-ruecktrittserklaerung-von-oezil-im-wortlaut

Perspective Daily [@PDmedien]. (2018, July 24). Ali Can kämpft als Gründer der 'Hotline für besorgte Bürger' gegen Vorurteile und Alltagsrassismus. Nun steht er hinter einem neuen Hashtag gegen die Diskriminierung von Menschen mit Migrationshintergrund [Ali Can, as founder of the 'Hotline for 
concerned citizens', fights against prejudice and everyday racism. Now he stands behind a new hashtag against discrimination of people with migration background] [Tweet]. Retrieved from https://twitter. com/PDmedien/status/1021805180214497285

Phillips, W. (2018). The oxygen of amplification. Better practices for reporting on extremists, antagonists, and manipulators. New York, NY: Data \& Society Research Institute. Retrieved from https://datasociety. net/library/oxygen-of-amplification

Rambukkana, N. (2015). \#Introduction. Hashtags as technosocial events. In N. Rambukkana (Ed.), Hashtag publics. The power and politics of social networks (pp. 1-10). New York, NY: Peter Lang.

Reckwitz, A. (2017). Gesellschaft der Singularitäten [Society of singularities]. Berlin: Suhrkamp.

Roberts, M. E., Stewart, B. M., \& Tingley, D. (2016). Navigating the local modes of big data: The case of topic models. In R. M. Alvarez (Ed.), Computational social science: Discovery and prediction (pp. 51-97). Cambridge: Cambridge University Press.

Roberts, M. E., Stewart, B. M., \& Tingley, D. (2019). stm: An $r$ package for structural topic models. Journal of Statistical Software, 91(1), 1-40.

Rogers, L. (1940). The pollsters. Public opinion, politics, and democratic leadership. New York, NY: Alfred A. Knopf.

Rosanvallon, P. (2008). Counter-democracy: Politics in an age of distrust. Cambridge: Cambridge University Press.

Rosenberg, D. (2018). Data as word. Historical Studies in the Natural Sciences, 48(5), 557-567.

Schofield, A., Magnusson, M., \& Mimno, D. (2017). Pulling out the stops: Rethinking stopword removal for topic models. In M. Lapata, P. Blunsom, \& A. Koller (Eds.), Proceedings of the 15th Conference of the European Chapter of the Association for Computational Linguistics: Volume 2, Short Papers (pp. 432-436). Stroudsburg, PA: Association for Computational Linguistics.

Schofield, A., \& Mimno, D. (2016). Comparing apples to apple: The effects of stemmers on topic models. Transactions of the Association for Computational Linguistics, 4, 287-300.

Splichal, S. (2012). Public opinion and opinion polling: Contradictions and controversies. In C. Holtz-Bacha \& J. Strömbäck (Eds.), Opinion polls and the media. Reflecting and shaping public opinion (pp. 25-46). New York, NY: Palgrave Macmillan.

Topçu, C. (2018, September 11). Diskussion um \#metwo [Discussion about \#metwo]. Deutschland.de. Retrieved from https://www.deutschland.de/de/topic/ leben/metwo-ali-can-loest-debatte-um-integrationin-deutschland-aus

Ulbricht, L. (2020). Scraping the demos. Digitalization, web scraping and the democratic project. Democratization, 27(3), 426-442.

Urbinati, N. (2019). Me the people: How populism transforms democracy. Cambridge, MA: Harvard University Press.

van Dijck, J., \& Poell, T. (2013). Understanding social media logic. Media and Communication, 1(1), 2-14.

Wang, T. (2013). Big data need thick data. Ethnography Matters. Retrieved from http://ethnographymatters. net/blog/2013/05/13/big-data-needs-thick-data

Yang, G. (2016). Narrative agency in hashtag activism. The case of \#blacklivesmatter. Media and Communication, 4(4), 13-17.

\section{About the Authors}
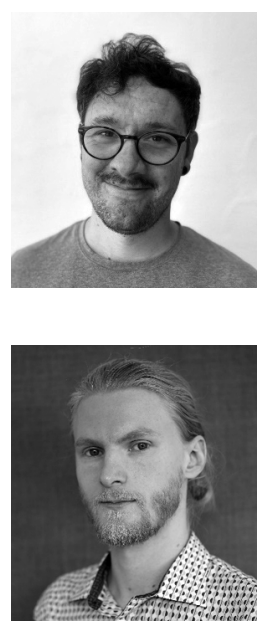

Tim König holds a Bachelor's degree in Political Sciences and a Master's degree in Social Sciences. His work focuses on the intersection of political theory and quantitative methods. In applying (big) data analyses to the measure of theoretical concepts, he is looking to close the epistemic gap between political theory and computational methods. He is currently pursuing a PhD in Political Sciences at the University of Hildesheim's interdisciplinary EPINetz Project.

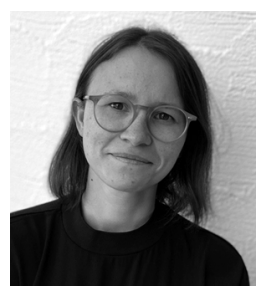

Ann-Kathrin Koster holds a degree in Political Science and Gender Studies (MA). She is a Doctoral Candidate in Political Science at the Schaufler Kolleg of the Technical University of Dresden with a research focus on the relation between artificial intelligence and concepts of radical democratic agency. 